Madrygal. Revista de Estudios Gallegos

ISSN: 1138-9664

\title{
A praxe da memoria histórica: o monumento de Pepe Galán
}

\author{
John Thompson ${ }^{1}$
}

Recibido: 15 de outubro de 2019 / Aceptado: 4 de novembro de 2019

Resumo. Erixidos desde o final do século pasado, os monumentos que simbolizan os crimes fascistas desempeñan un papel problemático no proceso da recuperación da memoria histórica. A grande maioría deles abandonáronse, de modo que é máis probábel que funcionen en contra da memoria que a prol dela. Unha excepción é a obra de Pepe Galán colocada no valigato que desemboca na cala do Portiño na cidade da Coruña. O monumento alude ao masacre dun grupo de militantes de esquerda que tentaron fuxir en marzo de 1937 desde O Portiño a Asturias. Para conseguir que unha obra como a de Galán funcione, cómpre un grande esforzo que ten que vir principalmente das asociacións de memoria e dos institutos. Este monumento nunca foi analizado malia posuír potencial para avanzar a causa da memoria histórica. Esta situación de desleixo pódese transformar nunha oportunidade para sensibilizar a sociedade, e sobre todo a xuventude, cara ao trauma causado polo fascismo.

Palabras chave: Memoria histórica; guerra civil española; franquismo; monumentos conmemorativos; lugares de memoria.

\section{[es] La praxis de la memoria histórica: el monumento de Pepe Galán}

Resumen. Erigidos desde el final del siglo pasado, los monumentos que simbolizan los crímenes fascistas desempeñan un papel problemático en el proceso de la recuperación de la memoria histórica. La gran mayoría de ellos se han abandonado, de manera que es más probable que funcionen en contra de la memoria que a favor de ella. Una excepción es la obra de Pepe Galán colocada en el pequeño valle que desemboca en la cala de O Portiño en la ciudad de A Coruña. El monumento alude a la masacre de un grupo de militantes de izquierda que intentaron huir en marzo de 1937 desde O Portiño a Asturias. Para conseguir que una obra como la de Galán funcione, se necesita un gran esfuerzo que tiene que venir principalmente de las asociaciones de memoria y de los institutos. Este monumento nunca fue analizado a pesar de poseer potencial para avanzar la causa de la memoria histórica. Esta situación de abandono se puede transformar en una oportunidad para sensibilizar a la sociedad, y sobre todo a la juventud, hacia el trauma causado por el fascismo.

Palabras clave: Memoria histórica; guerra civil española; franquismo; monumentos conmemorativos; lugares de memoria.

\section{[en] The Praxis of Historical Memory: Pepe Galán’s Memorial}

Abstract. Erected since the end of the last century, memorials that symbolize fascist crimes have played a problematic role in the process of recovering historical memory. The large majority of them have been abandoned, hence it is more probable that they work against memory than for it. One exception is Pepe Galán's work, which is located in a small valley that leads to the little bay of O Portiño, which is part of A Coruña city. The monument alludes to the massacre of a group of leftist militants that attempted to escape from O Portiño in March of 1937. Their intent was to reach Asturias. In order for a memorial as Galan's to work, great efforts are needed that must come from the asociacións de memoria and from high schools. This monument has never been analyzed despite possessing potential for advancing the cause of historical memory. This situation of abandonment can transform into an opportunity that sensitizes society, especially the youth, to the trauma caused by fascism.

Keywords: Historical memory; the Spanish Civil War; Francoism; Memorials; Commemoration; Memory sites.

Sumario. 1. A fuxida frustrada e a reivindicación da súa memoria. 2. O fetichismo e a perda da memoria. 3. Praxe e utopía no monumento de Pepe Galán. 4. O desafío. 4. Referencias bibliográficas.

Como citar: Thompson, J. (2019): “A praxe da memoria histórica: o monumento de Pepe Galán”, en Madrygal. Revista de Estudios Gallegos 22, pp. 285-292.

1 Montana State University, Department of Modern Languages \& Literatures.

Correo-e: john.thompson166@gmail.com 
Erixidos desde o final do século pasado, os monumentos que simbolizan os crimes fascistas desempeñan un papel problemático no proceso da recuperación da memoria histórica. A grande maioría deles abandonáronse unha vez inaugurados, e máis que símbolos do recordo agora son recordos do esquecemento. Os marcadores materiais da memoria son complexos e é máis probábel que funcionen en contra da memoria que a prol dela. Unha excepción é a obra de Pepe Galán colocada no valigato que desemboca na cala do Portiño, localizado na cidade da Coruña. O monumento alude ao masacre dun grupo de militantes de esquerda que tentaron fuxir desde O Portiño até Asturias, aínda na legalidade republicana.

Feito en aceiro dunha cor entre vermello e laranxa debido ao óxido, o monumento é unha pasarela de vinte metros de longo e dous metros de largo. A pasarela apunta ao mar e ten escadas nos dous extremos, unhas que descen cara ao mar e outras que soben na dirección oposta. No medio aparecen en chumbo os nomes dos fuxidos asasinados, e acima deles dous focos de luz azulada sostidos por postes de alumíneo de sete metros. Cando chega o anoitecer, os focos acéndense e un deles chisca en intervalos duns cinco segundos.
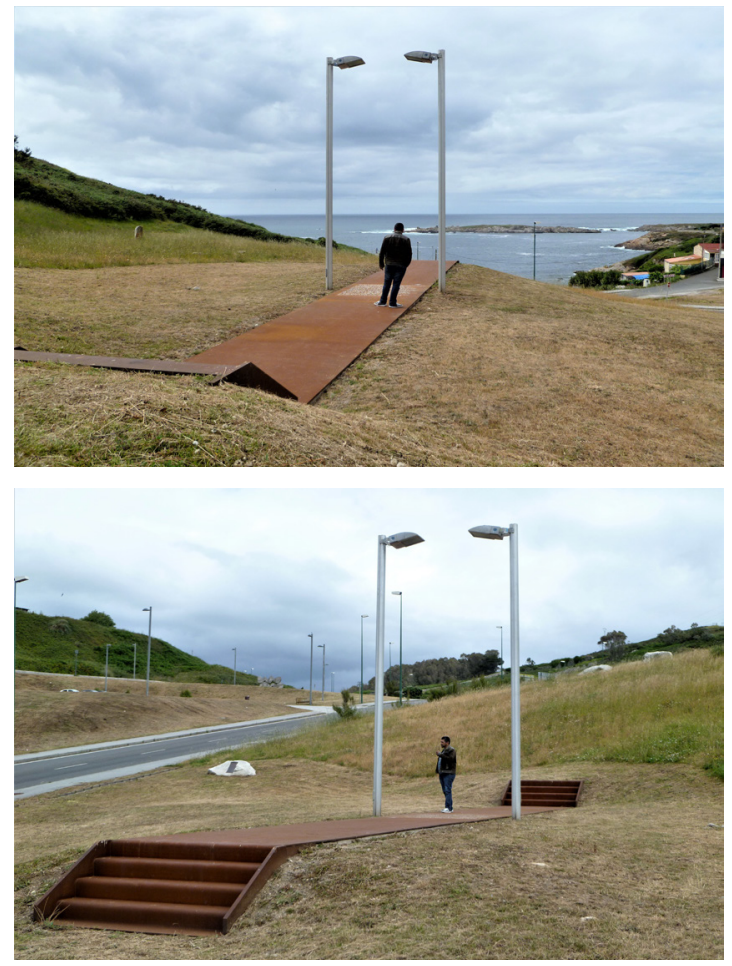

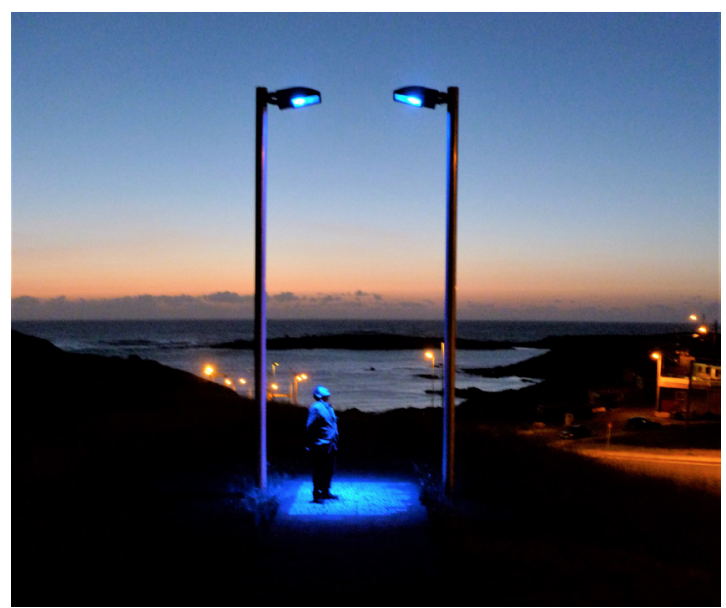

Monumento de Pepe Galán (fotos de John Thompson)

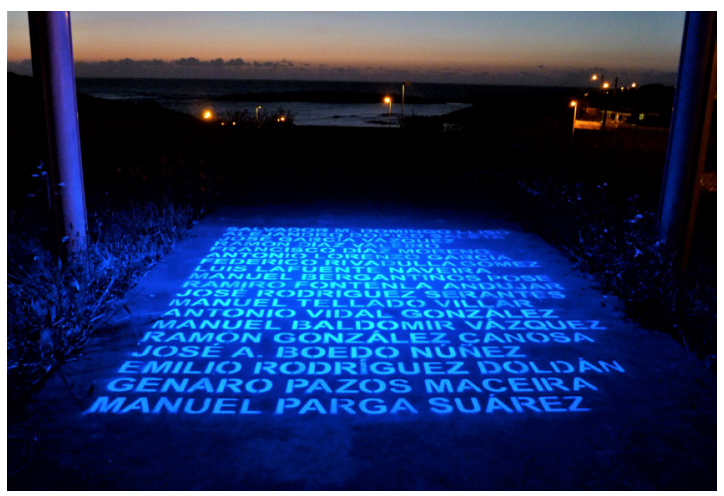

Este monumento, erixido en 2008, nunca foi analizado malia posuír potencial para avanzar a causa da memoria histórica ${ }^{2}$. Os lugares simbolizados poden ser acicates para unha comunidade manter a súa memoria; son patrimonio material e resisten o paso do tempo, sobre todo se se tratar dos lugares onde aconteceron os feitos. Estes denomínanse "lugares de represión" e a súa forza deriva do seu valor testemuñal dos crimes. Os monumentos levantados despois dos feitos, neste caso no posfranquismo, adoitan ter menos poder evocador, unha vez que a súa razón de ser non é fornecer autenticidade aos feitos, senón interpretalos.

Recordo a construción de Pepe Galán como a primeira na que reparei cando decidín facer un estudo sobre os monumentos conmemorativos en Galiza. Orballaba e anoitecía entre lusco e fusco, e impactáronme as lámpadas que creaban unha aura azul. Quería baixar ver todo de perto, mais o orballo converteuse en choiva e daquela tiven que adiar a visita para outra ocasión.

2 Amaya Caunedo fai un breve resumo das características do monumento e do suceso que representa, mais trátase dun texto descritivo, non analítico (2013: 79-80). 


\section{A fuxida frustrada e a reivindicación da súa memoria}

Chovía tamén a noite do masacre do tres de marzo de 1937. O sindicato anarquista "El Despertar Marítimo" organizou unha fuxida para aproximadamente cen persoas perseguidas polo recentemente instaurado réxime fascista. Os fuxidos agardaban en botes para que, cando se dese o sinal, alcanzasen dous bous que supostamente os esperaban mar afora (Pereira 2009: 130, Fernández 2009a: 164). A meta era chegar a Asturias, que aínda non caera en mans dos sublevados. Porén, o escape non se puido levar a cabo porque a Garda Civil descubriu o plano. Disparando contra os fuxidos, estes escaparon "gabeando monte arriba entre rochas e toxeiras", ou abeirando a costa "quer a nado, quer nalgunha buceta que xa estivese preparada" (Pereira 2010: 410). Antón Patiño, unha testemuña ocular do evento, describe: "Os homes trataban de fuxir dos disparos nadando ou subindo por penedos e rochas. Algúns foron presos, bastantes feridos e outros aparecerían aboiados nas praias e cantís días despois" (2005: 72). Vinte e sete foron detidos, quince fusilados, un morreu no cárcere e polo menos tres afogaron. Dos asasinados, tres das vítimas tiñan menos de vinte e un anos (Lamela 1998: 119, Fernández 2009b: 190191, Pereira 2009: 130 e 2010: 410).

Até 2005 este evento era practicamente descoñecido. A memoria existía de xeito espectral como se mostra na reflexión de Fernando Souto que, natural do bairro dos mariñeiros a carón do Portiño, escribe que na súa familia se falaba do evento, mais sen explicar como e por que acaeceu, e sen especificar como se chamaban os fuxidos: "Eu non sabía por que estaban fuxidos, de que fuxían, por que os perseguían, mais si tiña a sensación de que eran boa xente" (2009: 5).

O motor atrás da reivindicación do Portiño foi Antón Patiño. En 1996 a súa iniciativa deuse a coñecer nun artigo de Xosé Luís Méndez Ferrín publicado no Faro de Vigo
(Souto 2005). En 2005 Patiño publicou o seu libro testemuñal Memoria de Ferro e contactou coa Comisión pola Recuperación da Memoria Histórica da Coruña $(\mathrm{CRMH})$, e foi através das presentacións do libro organizadas por este grupo como se decidiu levantar un monumento (Monge 2008, Ventureira 2007). A Comisión organizou un concurso de ideas e presentáronse varios proxectos. Os concursos, moi comúns en Alemaña no que respecta á creación de marcadores referidos ao Holocausto, no se fixeron en Galiza agás neste caso. A vantaxe dos concursos é que abren o proceso de monumentalización á cidadanía. E se se producir un debate social, o proceso permea aínda máis o foro público.

A historia do Portiño no posfranquismo tamén incide na nosa análise. En 1977, o Concello da Coruña decidiu converter o lugar nun vertedoiro. Sería imposíbel atopar unha metáfora máis apta para a ocultación da memoria histórica. No mesmo período en que os adeptos da ditadura destruían a eito documentos comprometedores, tapar o val con 200.000 toneladas de lixo foi unha iniciativa brillante para se desfacer dun lugar simbolizado polo trauma, aínda que o simbolismo naquel tempo fose fragmentario e desartellado. "Era un lugar", contou Galán, "cheirón como podía ser en Pontevedra a ENCE; dependía de como sopraba o vento, viñan os cheiros para A Coruña" (entrevista co autor). Debido á saturación inxente, en setembro de 1996 o vertedoiro derrubouse e levou pola fronte carros, barcos e matou un home cuxo corpo nunca apareceu. Segundo Galán, a derruba "foi como un volcán sen lava" (entrevista) ${ }^{3}$.

Esta transformación de trauma en lixo recorda, aínda que á inversa, a renovación da illa de San Simón que, efectuada entre 1998 e 2005, converteu o meirande símbolo dos crimes fascistas en Galiza nunha fantasía tropical presidida por Jesús Pérez Varela, César Portela e o Capitán Nemo. Aquí, no canto de lixo, foi beleza e exotismo que serven a mesma función de soterrar os recordos que poidan ameazar o sistema ${ }^{4}$.

Esta interpretación do lixo como un soterramento do trauma non se pode probar empiricamente, visto que para iso farían falta documentos escritos ou testemuños orais que puidesen verificala. Con todo, consideramos que non se debe desbotar esta apreciación porque a iniciativa de crear o vertedoiro se realizou cando aínda restaban abundantes testemuñas directas do evento cuxos recordos eran molestos para a casta política, afervoada defensora do esquecemento abandeirado pola monarquía constitucional. Tampouco excluímos a posibilidade de que a decisión de enviar o lixo ao Portiño fose influída polo inconsciente colectivo condicionado pola narrativa do tardofranquismo, que promovía a supresión dos feitos e a memoria. Esta hipótese é coherente coas decisións tomadas na transición á democracia e coa política da desmemoria - que chega até os nosos días- executada polo Partido Socialista Obrero Español.

$4 \quad$ Sobre esta desfeita da memoria, véxase Thompson 2017. 
Mesmo así, é preciso diferenciar entre estes tipos de ocultacións, que son reversíbeis (en maior ou menor grao), e as destrucións de lugares de memoria que son irreversíbeis. A máis danosa en España foi a demolición da praza de touros de Badaxoz, sen dúbida o maior símbolo do exterminio franquista, ideada e executada por Juan Carlos Rodríguez Ibarra.

A recuperación do Portiño foi un fito para o movemento da memoria histórica en Galiza. Canda a inauguración, houbo actos con persoeiros da esquerda que axudaron a espallar o coñecemento da historia traumática; e para os familiares e achegados das vítimas que asistiron a esta reivindicación pública dos seus seres amados, o monumento supuxo un aceiramento de orgullo e ánimo. Mesmo así, é preciso recoñecer unha falla seria que prevalece en practicamente todos os proxectos e actos do movemento memorialista de todo o Estado: a grande ausencia da mocidade. Esta realidade é un claro indicio de que a memoria histórica, se non se tomaren medidas inmediatas e radicais, vai morrer talvez na cuarta xeración e seguramente na quinta 5 .

\section{O fetichismo e a perda da memoria}

Robert Musil iniciou en 1957 unha liña crítica cara ao fenómeno dos monumentos. As súas observacións son demoledoras: "Non hai nada neste mundo tan invisíbel como un monumento (...) están impregnados de algo que nos repele (...) Non se pode dicir que non nos fixamos neles, senón que eles non se fixan en nós, eluden as nosas facultades perceptivas (...) incítannos a vandalizalos" (1957: 61-62) ${ }^{6}$. Aínda que acertado, este discurso é determinista; non abre a porta a outras formas de crear e usar os monumentos.

James Young, unha figura eminente neste eido, desconfía tamén dos monumentos; por exemplo: "[A] memoria sen consecuencias contén as sementes da súa propia destrución" (1994: 15) ${ }^{7}$. As súas análises sobre as construcións estéticas que representan os eventos e as vítimas do Holocausto son igual de aplicábeis -e mesmo máis- aos monumentos galegos e aos do resto do Estado. O que diferencia Young de Musil é que defende unha posición en xeral favorábel, malia as súas sospeitas, cara aos monumentos. Nós defendemos unha posición non determinista mais tampouco tan positiva. As pescudas que fixemos sobre esta cuestión leváronnos a non confiar nas construcións simbólicas. Encanto para Young un monumento é efectivo se conseguir atraer a atención dos transeúntes, para nós só é efectivo se desempeñar un rol transformador, se se usar como impulsor para avanzar a causa da memoria histórica. $\mathrm{O}$ discurso de Young, pola contra, semella querer conter o potencial revolucionario da memoria.

O obstáculo principal a respecto da efectividade dos monumentos é o fetichismo. $\mathrm{O}$ fetichismo consiste en atribuír aos obxectos propiedades que non teñen; daquela no caso dos monumentos, os axentes da memoria tenden a pensar que axudan a manter viva a memoria pola simple razón de estaren colocados. A reflexión de Antón Figueroa bota luz sobre a cuestión:

Estamos nun país onde se "recollen" e "salvan" cantidade de fetiches, mentres a historia corre por outro lado. Parece que neste país todo o mundo está a escavar para logo gardar; continuamente estamos asistindo á presentación de alfaias de todo tipo que "de non ser polo esforzo de X, se perderían para sempre...." Nunha situación coma esta, iso é lóxico, e mesmo ás veces necesario. O máis grave de todo é que se pense que iso é o mellor e o único que se pode e debe facer. Cando a escavación se converte na única posibilidade de cultura, o que en realidade se fai é enterra-las posibilidades que quedaban. (1988: 13)

Do mesmo xeito que un libro non lido é un libro inútil, pódese afirmar o mesmo verbo dos monumentos. Se estes non son visitados e interpretados, non valen para nada. O exalcalde da Coruña Francisco Vázquez deu un exemplo de fetichismo digno de traer a consideración.

A primeira xeración -case desaparecida no ano en que se escribe este artigo (2019)- son as persoas que viviron a guerra civil e con suficiente idade para teren recordos da época. A segunda xeración, entre oitenta e cinco e cincuenta e cinco anos, naceu ou no final da contenda ou no inicio da ditadura. A terceira xeración naceu ou no final da ditadura ou ao principio do posfranquismo. A cuarta xeración son os bisnetos das testemuñas directas da guerra e os primeiros da quinta veñen de nacer ou están a piques. Véxase Valverde 2014: 69-79, quen explica as características das diferentes xeracións.

6 Tradución miña do inglés. A obra orixinal está en alemán.

Tradución miña do inglés. 
Cando lle perguntamos se ía sobrevivir o galego ou non, respondeu: "Sí, posiblemente. Yo soy bilingüe, yo hablo gallego y hablo castellano. Conozco el gallego y conozco el castellano. Tengo además una gran biblioteca en lengua gallega de cerca de mil volúmenes" (entrevista co autor).

A observación de Figueroa aplícase sen fisuras ao fenómeno dos monumentos, só que no canto de escavar trátase de levantar. O material conmemorativo non entra en nós, non lembra por nós. As persoas teñen que entrar nos monumentos para estes significaren algo. Só funcionan, daquela, se foren catalizadores de diálogo e debate.

É por isto que cando mellor poden funcionar os monumentos é antes de levantárense. Isto demostrouse co monumento de Valdi, localizado na Avenida de Navarra na cidade da Coruña. A causa da oposición creada polos sectores reaccionarios á memoria histórica, representados polo PSdeG e mais o PPdeG, e grazas á afouteza dos promotores agrupados na CRMH, creouse un debate que atinxiu abondosa visibilidade mediática. Através da pugna dialéctica, espalláronse os valores republicanos e normalizouse, até certo punto, o debate público verbo da memoria histórica. Porén, unha vez acadado o dereito de erixir a obra, desapareceu ese debate e esa pugna ${ }^{8}$.

\section{Praxe e utopía no monumento de Pepe Galán}

A praxe dun discurso teórico ou artístico realízase cando se reúnen no discurso un concepto abstracto e unha idea concreta que xuntos xeran un mapa de acción que de ser implementado pode contribuír a socavar as estruturas de opresión. Na memoria histórica, o elemento abstracto é a historia e a memoria (como fenómenos xenéricos) encanto o concreto son os proxectos que representan e utilizan parcelas da historia e da memoria. De seren ben sucedidos os proxectos, a súa praxe pode provocar na sociedade unha transformación cognitiva, unha praxe de pensamento.

Como ferramentarevolucionaria, a praxe naceu no pensamento marxista. Un representante desta liña teórica, Luis González, escribe que a praxe é "conocer la lógica estructural del modo de producción capitalista; criticar los efectos deshumanizadores de la misma y proponer - desde ese saber y esta crítica- un proyecto de sociedad en el que esa lógica fuese superada en sus raíces" (1991: 197). Trátase daquela de vencellar o coñecemento coa crítica da realidade (praxe de pensamento) e executar un plano de acción alicerzado nese coñecemento e posicionamento ético (praxe política). Para a praxe transformar a realidade é preciso que da contemplación se pase á acción (Adorno 1962: $23)^{9}$.

A estrutura base de calquera praxe e pensamento dialéctico é un binario conceptual ${ }^{10}$. No monumento de Galán hai tres binarios conceptuais que, artellados pola abstracción e a concreción, dan lugar á praxe do pensamento. $\mathrm{O}$ primeiro estabelécese entre o discurso escrito -a placa descritiva- e o discurso artístico. O primeiro constitúe o elemento concreto na medida en que evoca un evento específico e empiricamente demostrado; o segundo é a representación abstracta dese feito ${ }^{11}$. A placa enmarca a interpretación da obra e constitúe o primeiro e indispensábel ingrediente para a funcionalidade da construción:

\section{MORTOS DO PORTIÑO}

Lembranza das persoas que deron a vida pola nosa liberdade o 3 marzo de 1937. Simboliza o acontecido no intento de fuxida dun cento de persoas polo mar do Portiño, a causa da represión franquista.

MONUMENTO: corredor de aceiro, que vai de sudeste a noroeste, con escadas de fuxido ou de reencontro, que soben ou baixan do monte, van ou veñen do mar.

TEXTO: pano de nomes con dezaseis fusilados, dous afogados e un morto na cadea; signos cuñados no chan de metal, recheos de chumbo, como o aplicado nos seus pasamentos.

LUZ AZUL DOS FAROIS: elemento secuencial semellante ao latexo do corazón, querendo representar con isto un xeito de presenza continua.

Camiñantes!

\footnotetext{
Sobre este asunto, véxase Thompson 2014.
}

Explicado este concepto noutras palabras, o teórico marxista Adolfo Sánchez Vázquez (militante socialista durante a guerra civil e exiliado en México) explica que a praxe é "el gozne en que se articula el marxismo en su triple dimensión de proyecto, crítica y conocimiento" (1985: 442).

10 Para Frederic Jameson o pensamento dialéctico consiste en inventar un espazo ou idea que transcende o Bo e o Mao que, sen esquecer esta diferenza, visa a comprensión das interrelacións entre os dous (1981: 234).

11 Distingo aquí a historia dun evento concreto e a historia como fenómeno xenérico e por tanto abstracto. 
Ollade o ceo!

Ulide o mar!

Sentide o vento!

Non esquezades a quen morreu pola liberdade!

Comisión pola Recuperación da Memoria Histórica da Coruña

Concello da Coruña

Ministerio da Presidencia

\section{A Coruña 12 de Abril de 2008}

A mensaxe é clara e a explicación permite ao visitante apreciar, aínda que de xeito restrinxido, o simbolismo (o discurso artístico), o cal abre a posibilidade de imaxinar o evento representado. A placa tamén estabelece límites a respecto da interpretación. Para este tipo de obras, a estética debe estar sempre ao servizo da memoria evocada. A liberdade total de interpretación é para a arte desvencellada dos crimes contra a humanidade ${ }^{12}$.

Unha das eivas serias que amosan moitos dos monumentos é a falta da explicación do simbolismo intencionado. E cando existen placas, as explicacións son decote ambiguas ou insuficientes; por exemplo, o espiral de Acisclo Manzano en Santiago, cuxa placa reza "Vae Victis 1936". En non poucos casos as lendas deturpan os feitos como sucede co monumento en Ares, elaborado por Miguel Couto, que alude ás vítimas na comarca que foron deportadas a Mauthausen: "Aos nosos veciños en Mauthausen" lese. O resultado é a suxestión de que as vítimas ou ben emigraron a Mauthausen ou mesmo foron alí de ferias. Como intervencións éticas e socio-políticas, os monumentos teñen que se defender de calquera trivialización. A todo custo se debe evitar caer no relativismo e sobre todo na mentira como ocorre en Ares e noutros lugares ${ }^{13}$.

Os outros dous binarios da obra de Galán conforman o miolo da imaxinación utópica. En termos xerais, a Utopía consiste en ter esperanza na posibilidade de dar volta ao sistema. Segundo o fundador dos Estudos Utópicos, Ernst Bloch, pensar a Utopía é soñar esperto -conscientemente- ao contrario do soño freudiano no que domina o inconsciente. Para Bloch, o obxectivo dunha Utopía revolucionaria é forxar un novo vieiro desde o soño individual ao soño colectivo "que sae para moldear o mundo externo polo menos para alivialo, polo menos como locus minoris resistentiae, ou mesmo como a instrumentalización para [atinxir] o obxectivo" (2000: 237) ${ }^{14}$.

A Utopía que nos concirne é ollar ao futuro no sentido contrario ao que propón a narración que se xestou na Transición ("todos tivemos a culpa") e adoptou con tenaz dedicación o PSOE. O discurso dominante deste partido parte da premisa de que este autoengano resolverá todos os conflitos políticos actuais e vindeiros. A ollada ao futuro implica xa que logo a aniquilación da historia traumática. Para o movemento memorialista, en contrapartida, o futuro nútrese dese pasado que serve como elemento transformador da sociedade actual e futura. O mantra neoliberal da "fin da historia" implica que non hai xa outro sistema mellor que o capitalismo tardío e por tanto acabouse a necesidade de coñecer a historia como un acervo que constrúe as sociedades. Trátase dunha fe cega na evolución positiva da sociedade non moi diferente da que alimentou o ascenso ao poder dos nazis.

No pensamento utópico que propón a obra de Galán entran dous elementos; primeiro, o sobe-baixa das escadas. As que baixan cara ao mar simbolizan os fuxidos perseguidos e baleados; as que soben na dirección contraria son os recordos do masacre que retornan. Esta dialéctica xunta o evento - $\mathrm{O}$ masacre- co recordo del; e isto conduce á concienciación social que se acada grazas ao coñecemento do crime e ao entendemento das súas causas e consecuencias.

Por súa vez, os faros e mais os postes que os sustentan xeran outro binario menos evidente, xa que os dous compoñentes non se producen simultaneamente. E é que o monumento ten dúas vidas por así dicir: de noite os faros iluminan os nomes dos asasinados, o que converte o monumento de maneira exclusiva nun lugar de

12 O único defecto que detectamos no texto da placa é a palabra "pasamentos", que suxestiona que non houbo vítimas e vitimarios. As vítimas foron fusiladas e cómpre expresalo sen eufemismos.

13 A placa máis ignominiosa do Estado é con certeza a do cemiterio de Badaxoz que adxudica a culpa do masacre tanto aos fascistas como aos republicanos: "El pueblo de Badajoz a todos sus hijos que perdieron la vida en ella y que aquí reposan con el deseo de que nunca más en el suelo hispano sucedan hechos como los que hace 50 años comenzaron".

14 Tradución miña do inglés, que é unha tradución do alemán orixinal. Esta obra referencial publicouse en 1923. 
conmemoración. De día, en contraste, os nomes non son tan aparentes e os elementos que destacan son as escadas, o horizonte e o océano ${ }^{15}$.

De día pódese imaxinar o cruzamento do pasado e presente -a fuxida das vítimas e o retorno dos seus recordos- simbolizado polas escadas. Ao mesmo tempo, os postes crean unha xanela que mapea a mensaxe do monumento sobre o horizonte. Por esta razón, é preciso facer dúas visitas para entender e apreciar mellor a obra. O máis efectivo é comezar coa visita nocturna porque o evento tivo lugar na noite. Desde o monumento séntese a presenza próxima do mar e ao ver os nomes iluminados pódese facer unha idea do que alí aconteceu. $\mathrm{O}$ faro que chisca como o latexo do corazón aumenta a ilusión da presenza das vítimas. O que impera nesta visita son daquela a conmemoración e a imaxinación en clave negativa.

A combinación de noite e día é a faceta do monumento que permite ir alén da praxe de pensamento e entrar no pensamento utópico. Pódense distinguir tres movementos: o primeiro é a baixada ao mar que acabou no masacre; o segundo é a volta da memoria que leva á concienciación social e o terceiro é voltar ao mar de día desde o pensamento e a ollada en clave positiva. É neste estado cando se soña esperto con ese mundo diferente do noso. Esta ollada semella ademais proxectar a memoria da fuxida frustrada ao resto do mundo, o que libera e universaliza os recordos e as visións democráticas das vítimas. O pensamento utópico é a consumación da praxe de pensamento e a fase previa á praxe política.

\section{O desafío}

Aínda que teoricamente se pode considerar o monumento de Pepe Galán un lugar de memoria, non o é porque non é visitado, agás contadas excepcións. Para conseguir que unha construción como a de Galán funcione, cómpre un grande esforzo que ten que vir principalmente das asociacións de memoria, dos institutos e das universidades. A política institucional pode tamén contribuír por medio de colaboracións puntuais.

É preciso expulsar a todo custo a concepción fetichista verbo dos monumentos. $\mathrm{O}$ fetichismo leva á mitoloxía (Adorno 1962: 16) e arruína a Utopía igual que a ansiedade afoga o sexo. Todos os monumentos sofren a mesma sorte, en maior ou menor grao, de abandono.

Unha opción para levar á práctica é converter a obra de Galán nun "lugar de conciencia". Liz Sevcenko explica que os lugares de conciencia teñen principalmente tres obxectivos: "[I]nterpretar a historia através dun lugar, crear programas que estimulen o diálogo en torno ás cuestiones sociais urxentes de hoxe e dar oportunidades para o envolvemento do público" (2011: 114) ${ }^{16}$.

O público máis importante é a mocidade. Sen a implicación dela, as tarefas actuais a prol da memoria histórica perden o seu potencial. Para os rapaces interesárense na memoria histórica hai que elaborar planos proactivos para integralos no movemento memorialista. É preciso darlles poder e as ferramentas para eles dirixiren os seus propios proxectos e crearen o seu propio patrimonio republicano. É fundamental que os rapaces deixen de ser receptores, como ocorre nas aulas, e pasen a ser actores ${ }^{17}$.

Se non se usan os monumentos como catalizadores de transformación política, son inúteis e contraproducentes. De símbolos da memoria deveñen en símbolos do esquecemento. Esta situación de desleixo pódese transformar nunha oportunidade para sensibilizar a sociedade, e sobre todo a xuventude, cara ao trauma causado polo fascismo. Se os rapaces non se implican, o país construirase sobre a mentira e a esquerda perderá as súas raíces. É agora ou nunca.

15 Hai que salientar a estética mesurada do monumento que non cae na estetización do trauma como acontece (opinamos) no monumento de Tomasz Lec en Varsovia, que representa a ponte que unía o gueto grande co gueto pequeno (véxanse fotos en "Warsaw Ghetto Bridge Memorial").

16 Tradución miña do inglés.

17 É preciso citar o cómic de Xosé Tomás, Compañeiros: Homenaxe ás vítimas do Portiño (publicado pola CRMH), que axudou a achegar o coñecemento do evento á mocidade. 


\section{Referencias bibliográficas}

Adorno, Theodor (1962): Prismas. Barcelona: Ariel.

Anónimo (2008): "Warsaw Ghetto Bridge Memorial. The Sad Story behind the Bridge", Breaking Free without Breaking the Budget 22/08/2008, https://thebudgetsavvytravelers.com/warsaw-ghetto-bridge-memorial/.

Bloch, Ernst (2000): The Spirit of Utopia. Stanford: Stanford University Press.

Caunedo, Amaya (2013): "Espacios y monumentos para el recuerdo de las víctimas en el norte", en C. Mir Curcó e J. Geloncho Sole (eds.), Duelo y memoria: Espacios para el recuerdo de las víctimas de la represión franquista en perspectiva comparada. Lleida: Edicions de la Universitat de Lleida, pp. 71-106.

Fernández, Eliseo (2009a): “A fuga do Portiño”, en E. Fernández (ed.), A fuxida do Portiño. Vigo: Promocións Culturais Galegas, pp. 159-170.

— (2009b): “As vítimas do Portiño", en E. Fernández (ed.), A fuxida do Portiño. Vigo: Promocións Culturais Galegas, pp. 185-213

Figueroa, Antón (1988): Diglosia e texto. Vigo: Xerais.

Galán, Pepe (2011): Entrevista co autor.

González, Luis Armando (1991): "El concepto de praxis en Marx: la unidad de ética y ciencia", Realidad: Revista de Ciencias Sociales y Humanidades 19, pp. 195-226.

Jameson, Frederic (1981): The Political Unconscious: Narrative as a Socially Symbolic Act. Ithica: Cornell University Press.

Lamela, Luís (1998): Estampas de injusticia: la guerra civil de 1936 en A Coruña y los documentos originados en la represión. Sada: Ediciós do Castro.

Monge, Manuel (2008): "Unha cuestión de xustiza", Gaceta do Portiño, marzo de 2008. A Coruña: A Comisión pola Recuperación da Memoria Histórica, p. 2.

Musil, Robert (1987): Posthumous Papers of a Living Author. Hygiene: Eridanos Press [versión orixinal en alemán en 1957].

Patiño, Antón (2005): Memoria de ferro. Vigo: A Nosa Terra.

Pereira, Dionisio (2010): Loita de clases e represión franquista no mar (1864-1939). Vigo: Xerais. (2009): "Os mártires do mar: unha achega á represión franquista contra os mariñeiros galegos”, en E. Fernández (ed.), A fuxida do Portiño. Vigo: Promocións Culturais Galegas, pp. 35-44.

Sánchez Vázquez, Adolfo (1985): "Mi obra filosófica”, en J. González, C. Pereyra e G. Vargos Lozano (eds.), Praxis y filosofia: Ensayos en homenaje a Adolfo Sánchez Vázquez. México DF: Editorial Grijalbo.

Sevcenko, Liz (2011): "Sites of conscience: Heritage of and for Human Rights", en H. Anheier e Y. Raj Isar (eds.), Heritage, Memory, and Identity. Newbury: Sage Publications, pp. 114-123.

Souto, Fernando (2009): "Prólogo", en E. Fernández (ed.), A fuxida do Portiño. Vigo: Promocións Culturais Galegas, pp. 5-6.

Souto, Xurxo (2005): “Os mortos do Portiño”, La opinión (A Coruña) 12/06/2005.

Thompson, John (2017): "From the Island of Trauma to Fantasy Island: The Renovation of San Simón", en B. Sampedro Vizcaya e J. A. Losada Montero (eds.), Rerouting Galician Studies: Multidisciplinary Interventions. Londres: Palgrave Macmillan, pp. 109-126.

(2014): "Os monumentos conmemorativos de Valdi na Coruña, Aranga e Santa Mariña (Guitiriz)", Murguía. Revista Galega de Historia 29-30, pp. 59-74.

Tomás, Xosé (2008): Compañeiros: Homenaxe ás vítimas do Portiño. A Coruña: A Comisión pola Recuperación da Memoria Histórica da Coruña, https://www.foroporlamemoria.info/2010/01/companeiros -homenaxe-as-vitimas-do-portino/.

Vázquez, Francisco (2010): Entrevista co autor.

Valverde, Clara (2014): Desenterrar las palabras: Transmisión generacional del trauma de la violencia política del siglo XX en el Estado español. Barcelona: Icaria editorial.

Ventureira, Rubén (2007): “Ocho propuestas para honrar a las víctimas de O Portiño”, La Voz de Galicia (A Coruña) 29/12/2007, https:/www.lavozdegalicia.es/noticia/coruna/2007/12/29/ocho-propuestas-honrarvictimas-portino/0003_6440828.htm.

Young, James (1994): The Texture of Memory: Holocaust Memorials and Meaning. New Haven: Yale University Press. 